\title{
Multimodal Artificial Neurological Sensory-Memory System Based on Flexible Carbon Nanotube Synaptic Transistor
}

Haochuan Wan, ${ }^{\dagger}$ Junyi Zhao, ${ }^{\dagger}$ Li-Wei Lo, ${ }^{\dagger},+$ Yunqi Cao, ${ }^{\S}$ Nelson Sepúlveda, ${ }^{\perp}$ and Chuan Wang ${ }^{*},+\$$

$\dagger$ Electrical and Systems Engineering and Institute of Materials Science and Engineering, Washington University in St. Louis, St Louis, Missouri 63130, United States

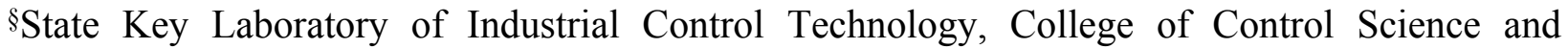
Engineering, Zhejiang University, Hangzhou, Zhejiang 310027, China

${ }^{\perp}$ Electrical and Computer Engineering, Michigan State University, East Lansing, Michigan 48824, United States

*Corresponding author: chuanwang@wustl.edu

\section{Supporting information}




\section{Multimodal sensory system circuit and device diagrams}

(a)
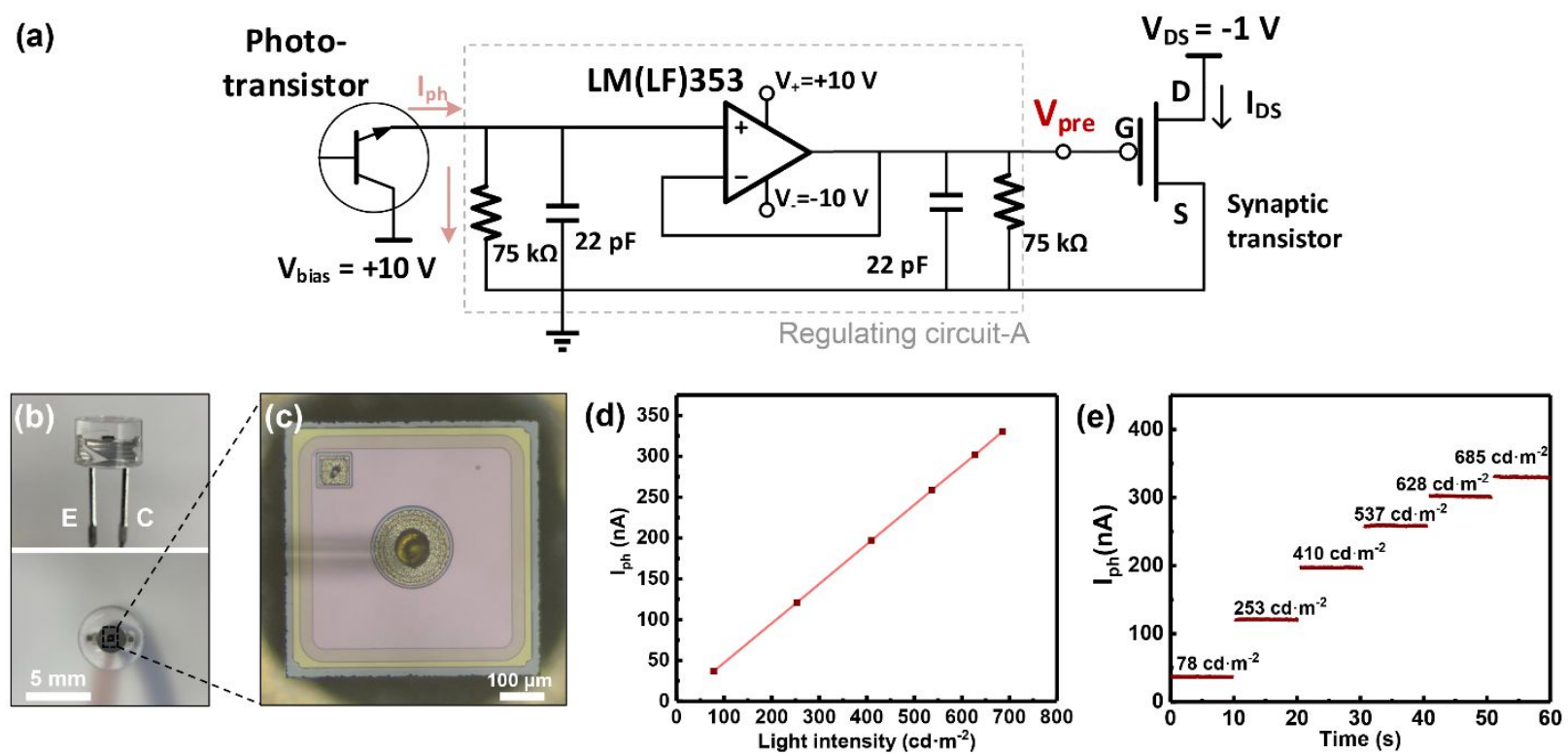

Figure S1. (a) Schematic diagram of the visual sensory-memory system circuit. (b) Photograph of the ambient-light phototransistor. Top: side view, bottom: top view. (c) Top view microscopic image of the phototransistor core. (d) Photocurrent versus incident light intensity characteristic curve. (e) Change in photocurrent over time under various incident light intensities.
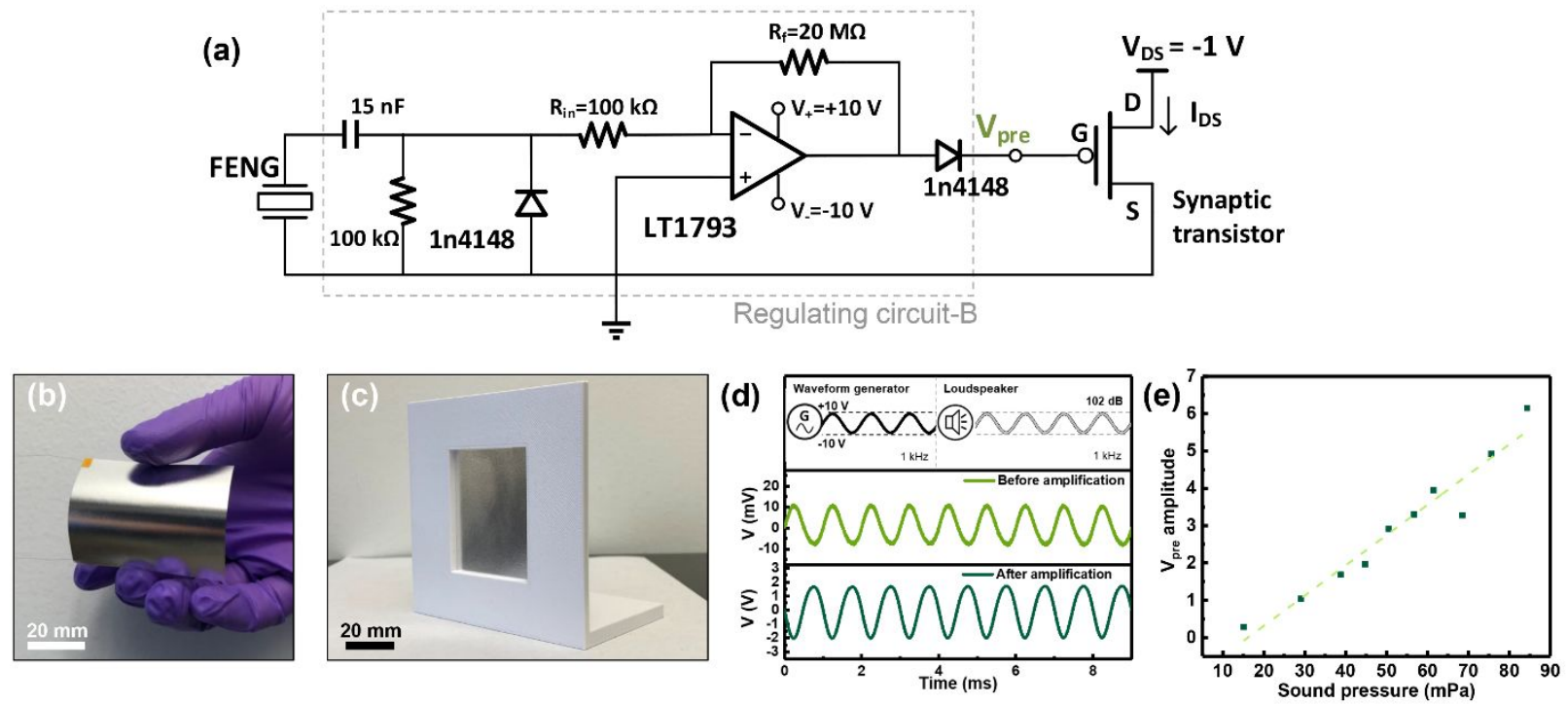

Figure S2. (a) Schematic diagram of the auditory sensory-memory system circuit. (b) Photograph of the FENG as acoustic sensor (before mounting on the scaffold). (c) Photograph of the FENG as acoustic sensor on the scaffold. (d) Sound vibration transduction test of FENG as acoustic sensor. (e) Plot of the amplitudes of auditory $V_{\text {pre }}$ versus the sound pressure calculated from the measured SPL level of input auditory stimuli. 
(a)

(a) $\quad \mathrm{V}_{\mathrm{DS}}=-\mathbf{1} \mathrm{V}$
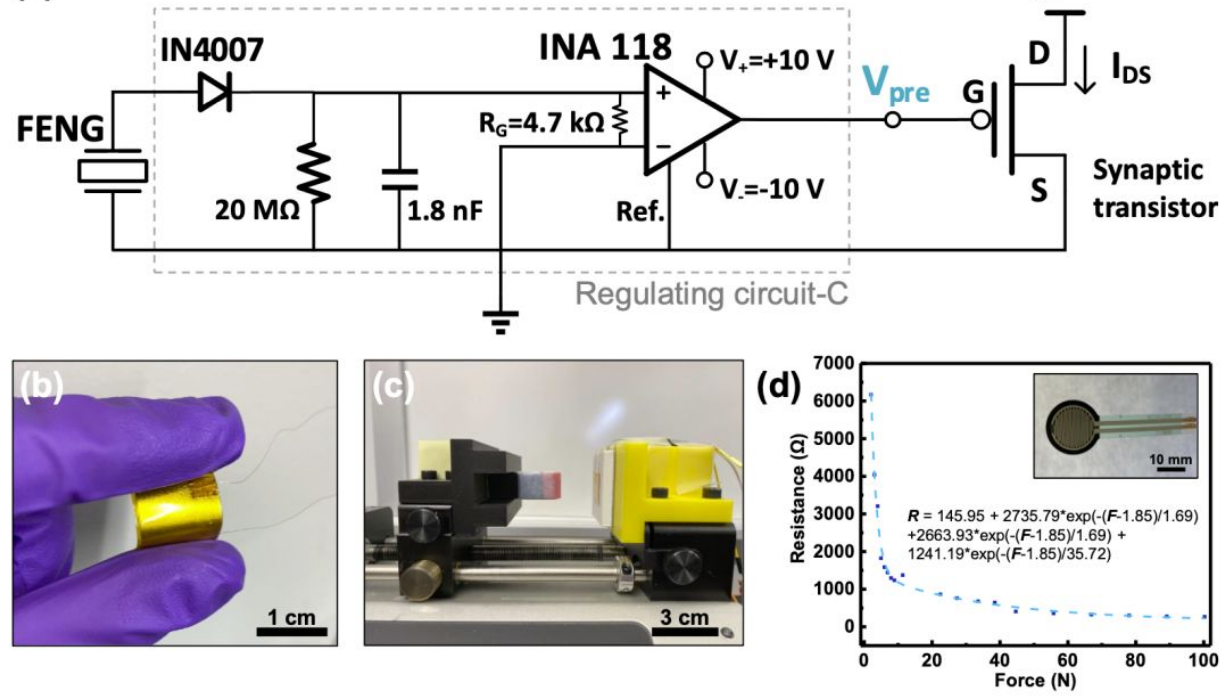

Figure S3. (a) Schematic diagram of the tactile sensory-memory system circuit. (b) Photograph of the FENG as tactile sensor. (c) Photograph of the mechanical loading test setup. (d) Calibration curve and fitting equation of the resistance change-based commercial force sensor $(\varnothing=0.5 \%$, force sensing resistor, POLOLU). Inset: photograph of the commercial force sensor. 


\section{Characterization of presynaptic action potentials}

\begin{tabular}{|c|c|c|c|}
\hline Stimulus type & Visual & Auditory & Tactile \\
\hline $\begin{array}{l}\text { Generation of the } \\
\text { physical stimuli }\end{array}$ & $\begin{array}{c}\text { Waveform generator } \\
\text { (square pulses, } 1 \mathrm{~Hz}, \\
1 \% \text { duty cycle, tunable } \\
\text { amplitudes) } \rightarrow \text { White- } \\
\text { light LED }\end{array}$ & $\begin{array}{c}\text { Waveform generator } \\
\text { (square pulses, } 1 \mathrm{~Hz}, \\
1 \% \text { duty cycle, tunable } \\
\text { amplitudes) } \rightarrow \\
\text { Loudspeaker }\end{array}$ & $\begin{array}{c}\text { Linear motor }(0.67 \mathrm{~Hz}, \\
\text { tunable moving } \\
\text { distances })\end{array}$ \\
\hline $\begin{array}{l}\text { Induced presynaptic } \\
\text { pulses }\left(V_{\text {pre }}\right)\end{array}$ & $\begin{array}{l}\text { Square pulses, } 1 \mathrm{~Hz}, 10 \\
\text { ms pulse width, various } \\
\text { amplitudes }\end{array}$ & $\begin{array}{l}\text { Composite triangular } \\
\text { pulses, } 1 \mathrm{~Hz}, 5 \sim 6 \mathrm{~ms} \\
\text { pulse width (major } \\
\text { peak), various } \\
\text { amplitudes }\end{array}$ & $\begin{array}{l}\text { Triangular pulses, } 0.6 \\
\mathrm{~Hz}, 180 \sim 200 \text { ms pulse } \\
\text { width, various } \\
\text { amplitudes }\end{array}$ \\
\hline $\begin{array}{c}\text { Switching polarity } \\
\text { of } V_{\text {pre }}\end{array}$ & $\begin{array}{l}\text { Toggle the two output } \\
\text { terminals of regulating } \\
\text { circuit-A that connect } \\
\text { to the G and } \mathrm{S} \text { of the } \\
\text { synaptic transistor }\end{array}$ & $\begin{array}{l}\text { Toggle the direction of } \\
\text { the diode that connects } \\
\text { to the G of the synaptic } \\
\text { transistor }\end{array}$ & $\begin{array}{l}\text { Toggle the two input } \\
\text { terminals of the } \\
\text { amplifier }\end{array}$ \\
\hline $\begin{array}{l}V_{\text {pre }} \text { amplitude }(V)- \\
\text { input stimulus } \\
\text { intensity }(s) \text { fitting } \\
\text { curve equation }\end{array}$ & $\begin{array}{c}V=0.0107 s-0.164 \\
\mathrm{R}^{2}=0.998\end{array}$ & $\begin{array}{c}V=0.00208 s^{3}- \\
0.375 s^{2}+23.0 s-480 \\
\mathrm{R}^{2}=0.953\end{array}$ & $\begin{array}{c}V=0.0547 s+1.937 \\
\mathrm{R}^{2}=0.972\end{array}$ \\
\hline
\end{tabular}

Table S1. Summary of multimodal generation process of physical stimuli, characterizations of $V_{\text {pre, }}$ polarity switching methods of $V_{\text {pre }}$ and $V_{\text {pre }}$ amplitude-stimulus intensity fitting equations. 


\section{Characteristics of the SSWCNT artificial synaptic transistor}
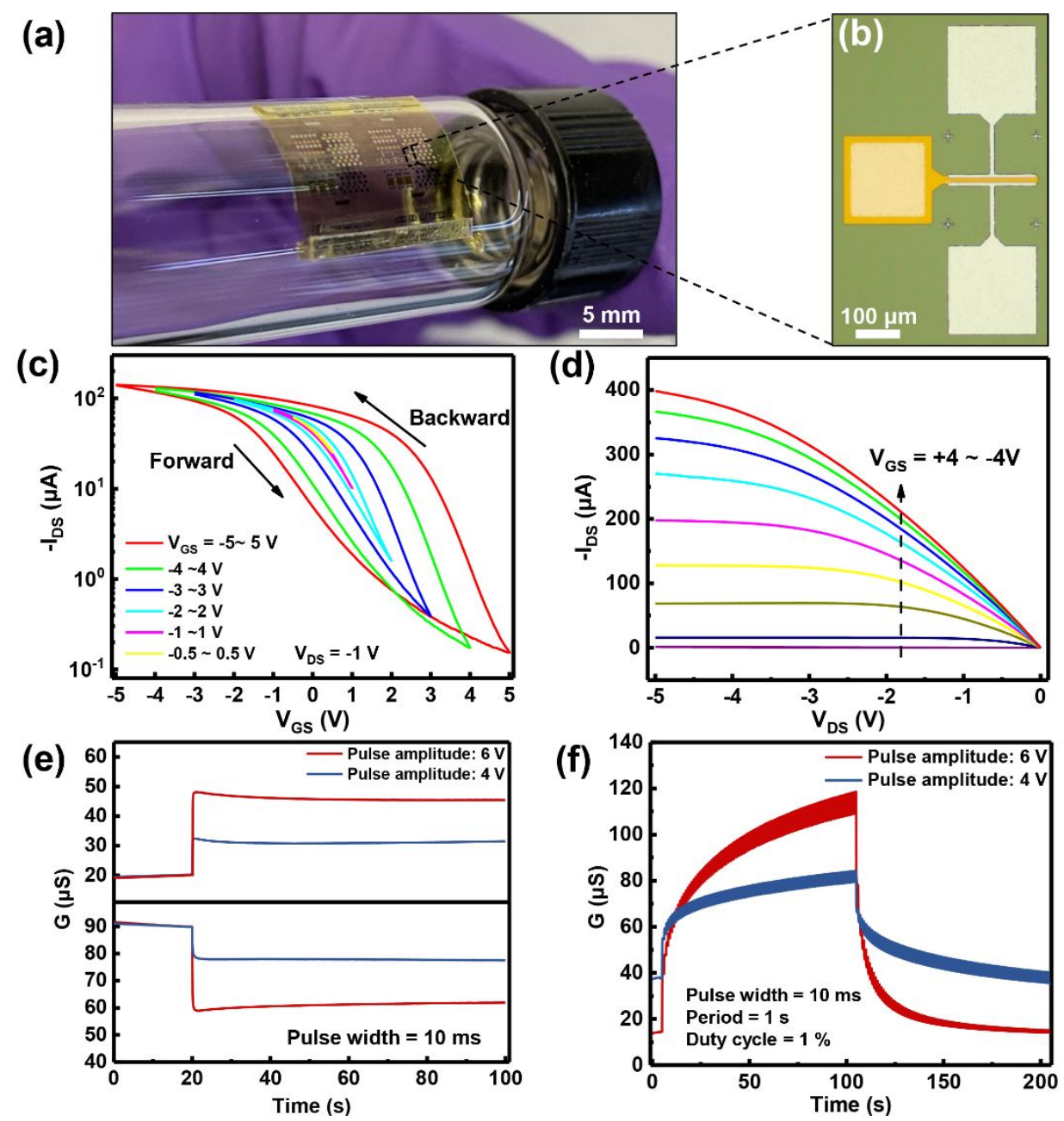

Figure S4. (a) Photograph of flexible sSWCNT synaptic transistors on polyimide substrate. (b) Microscopic image of a representative synaptic transistor with channel length $(L)$ of $10 \mu \mathrm{m}$ and channel length $(W)$ of $200 \mu \mathrm{m}$. (c) Bi-directional transfer curves $\left(I_{\mathrm{DS}}-V_{\mathrm{GS}}\right)$ of the synaptic transistor showing the levels of hysteresis under different ranges of $V_{\mathrm{GS}}$ sweeping. (d) Output curves $\left(I_{\mathrm{DS}}-V_{\mathrm{DS}}\right)$ of synaptic transistor. (e-f) Single-pulse plasticity curves (e) and conductance modulation (long-term plasticity) curves (f) of the sSWCNT artificial synaptic transistor induced by standard voltage pulses generated by waveform generator.

\begin{tabular}{rcccccc}
\hline $\boldsymbol{L}$ & $\boldsymbol{W}$ & $\boldsymbol{C}_{\mathbf{0 x}}$ & $\boldsymbol{g}_{\mathbf{m}} / \boldsymbol{W}$ & $\boldsymbol{\mu}_{\text {device }}$ & $\boldsymbol{I}_{\mathbf{0}} / \boldsymbol{W}$ & $\boldsymbol{I}_{\mathbf{0}} / \boldsymbol{I}_{\mathbf{o f f}}$ \\
\hline 10 & 200 & $7.45 \times 10^{-8}$ & 0.208 & 28.0 & 0.705 & \\
$\mu \mathrm{m}$ & $\mu \mathrm{m}$ & $\mathrm{F} / \mathrm{cm}^{2}$ & $\mu \mathrm{S} / \mu \mathrm{m}$ & $\mathrm{cm}^{2} \mathrm{~V}^{-1} \mathrm{~s}^{-1}$ & $\mu \mathrm{A} / \mu \mathrm{m}$ & 920 \\
\hline
\end{tabular}

Table S2. Basic transistor characteristics of the sSWCNT artificial synaptic transistor. 
Where $L$ is the channel length, $W$ is the channel width, $C_{\mathrm{ox}}$ is gate capacitance per unit area, $g_{\mathrm{m}} / W$ is normalized peak transconductance, $\mu_{\text {device }}$ is the field-effect device mobility, $I_{\text {on }} / W$ is the normalized on-current density, $I_{\mathrm{on}} / I_{\mathrm{off}}$ is the device on/off current ratio. The value of $g_{\mathrm{m}}$ is extracted from $I_{\mathrm{DS}}-V_{\mathrm{GS}}$ curve and the $\mu_{\text {device }}$ is calculated from the following equation:

$$
\mu_{\text {device }}=\frac{L \quad d I_{D S}}{V_{D S} C_{o x} W d V_{G S}}=\frac{L \quad g_{m}}{V_{D S} C_{o x} W}
$$

\section{Stability and reliability test of the sSWCNT artificial synaptic transistor}
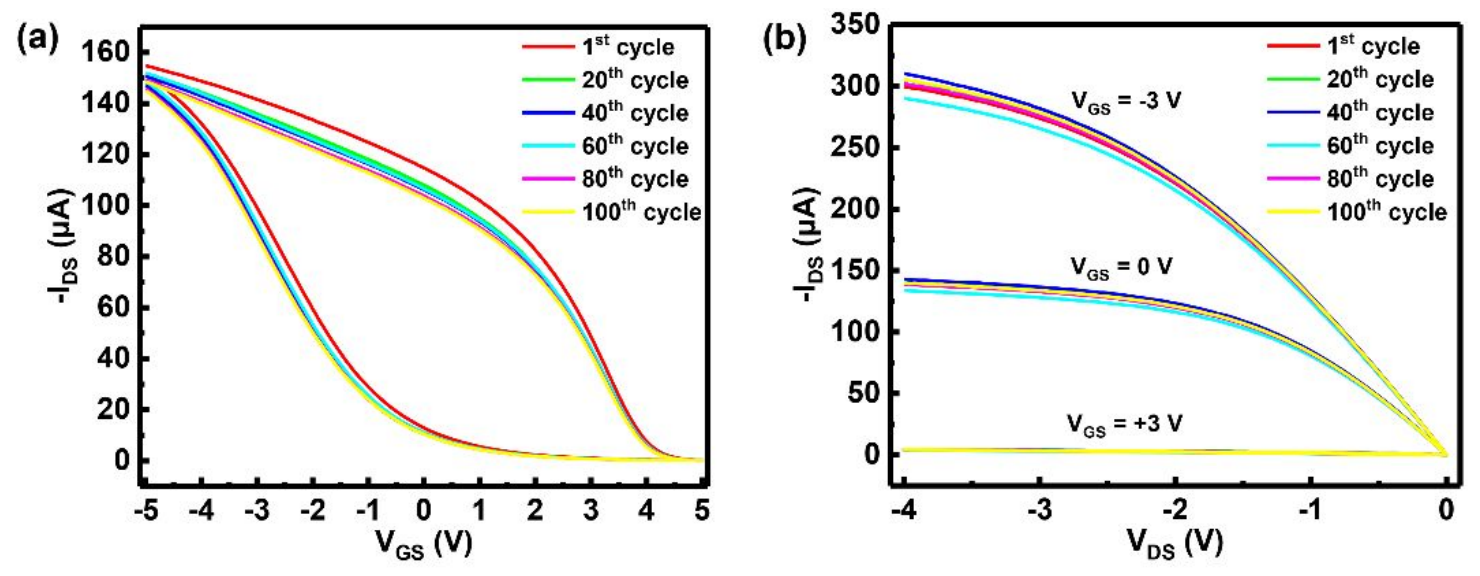

Figure S5. (a) Bi-directional transfer curves $\left(I_{\mathrm{DS}^{-}} V_{\mathrm{GS}}\right)$ of the synaptic transistor during 100 cycles of continuous measurement. (b) Output curves $\left(I_{\mathrm{DS}}-V_{\mathrm{DS}}\right)$ of synaptic transistor during 100 cycles of continuous measurement. 


\section{Estimation of energy consumption in the sSWCNT artificial synaptic transistor}

The energy consumption for a single synaptic operation can be estimated using the following equation:

$$
E=\int_{0}^{t} d E=\int_{0}^{t} V_{D S} \times\left(I_{D S}-I_{\text {baseline }}\right) \times d t
$$

Where $V_{\mathrm{DS}}$ is the drain-source voltage, $I_{\mathrm{DS}}$ is the drain-source current during the synaptic operation, $I_{\text {baseline }}$ is the stable drain-source current before the synaptic excitation and $t$ is the synaptic operation time.

In the sensory-memory system, we used a simplified scheme (shown in Figure S6a) to estimate the energy consumption. The blue line represents the synaptic response of the transistor. Here, the pulse width of the $V_{\text {pre }}$ is treated as operation time $t$. We assume that the $I_{\mathrm{DS}}$ reaches its peak at the end of the operation time and $I_{\mathrm{DS}}$ increases linearly with operation time. During the synaptic measurement, the $V_{\mathrm{DS}}$ is usually fixed, so the equation to estimate the energy consumption can be simplified as following:

$$
E=\frac{1}{2} V_{D S} \times\left(I_{D S}-\text { peak }-I_{\text {baseline }}\right) \times t
$$

Here we use the single-pulse plasticity curve of single visual $V_{\text {pre }}$ with light intensity of $230 \mathrm{~cd} \cdot \mathrm{m}^{-2}$ as an example to estimate the power consumption. From Figure $3 \mathrm{a}$, we can obtain $I_{\text {baseline }}=-2.7 \mu \mathrm{A}, I_{\mathrm{DS}-\text { peak }}=$ $15.7 \mu \mathrm{A}$ at $V_{\mathrm{DS}}=-1 \mathrm{~V}$. The pulse width of the visual $V_{\text {pre }}$ is around $10 \mathrm{~ms}$ so $t=10 \mathrm{~ms}$. Thus, we can estimate the energy consumption for a single visual synaptic operation using the data above and equation (2). The calculated energy consumption is $65 \mathrm{~nJ} /$ per spike. For $V_{\text {pre }}$ with light intensity of $672 \mathrm{~cd} \cdot \mathrm{m}^{-2}$, the energy consumption is $201.5 \mathrm{~nJ} /$ per spike.

However, the energy consumption of the synaptic transistor can be significantly lowered by using smaller $V_{\mathrm{DS}}$ and by using $V_{\text {pre }}$ with narrow pulse width (operation time). We measured the synaptic response of the transistor at $V_{\mathrm{DS}}=-5 \mathrm{mV}$ with pulse width of $1 \mathrm{~ms}$ and pulse amplitude of $+6 \mathrm{~V}$, the result is shown in Figure S6b. Under such operating conduction, we can obtain $I_{\text {baseline }}=-402.5 \mathrm{nA}, I_{\mathrm{DS}-\text { peak }}=-423.1 \mathrm{nA}$ at $V_{\mathrm{DS}}$ $=-5 \mathrm{mV}$ and $t=1 \mathrm{~ms}$ from Figure S6b. The corresponding estimated energy consumption is $51.5 \mathrm{fJ} /$ per spike. 
(a)

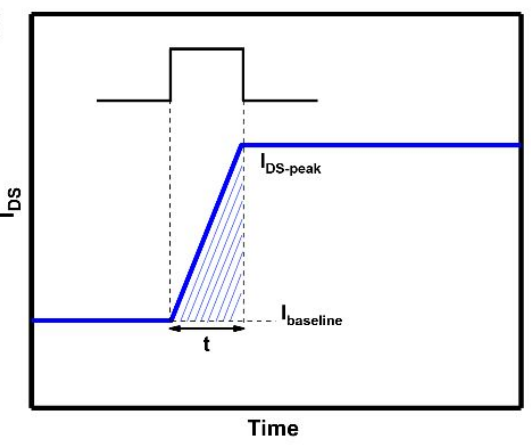

(b)

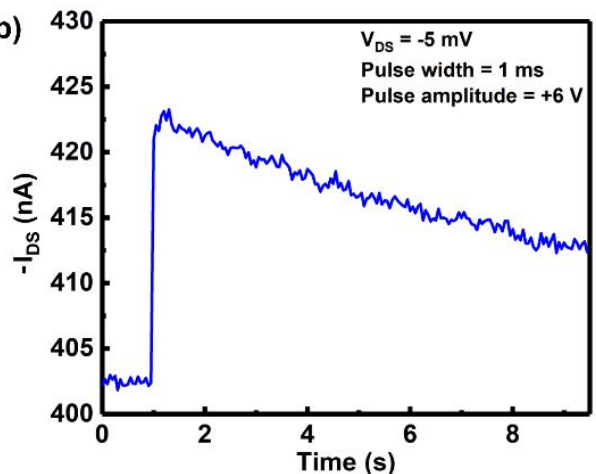

Figure S6. (a) Schematic illustration of the simplified energy consumption scheme in the sensory-memory system. (b) Single-pulse plasticity curve of the sSWCNT artificial synaptic transistor measured at $V_{\mathrm{DS}}=-5$ $\mathrm{mV}$ with a pulse width of $1 \mathrm{~ms}$ and a pulse amplitude of $+6 \mathrm{~V}$. 


\section{Single-pulse plasticity and long-term plasticity characterizations}
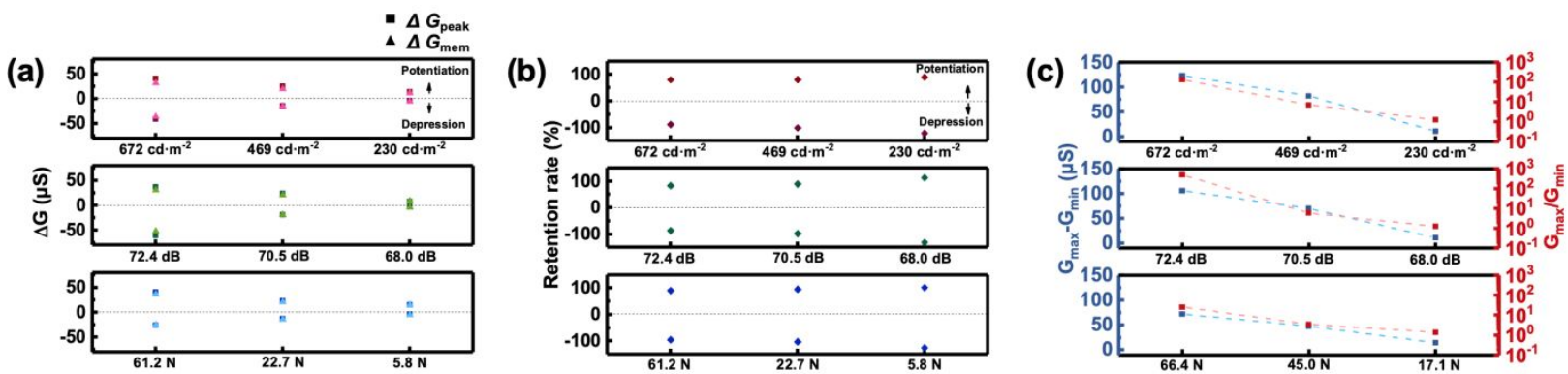

Figure S7. (a) Plots of conductance plasticity $\Delta G_{\text {peak }}$ and $\Delta G_{\text {mem }}$ induced by visual, auditory and tactile stimulus under different stimulating intensities. (b) Plots of retention rate $\left(\Delta G_{\text {peak }} / \Delta G_{\text {mem }} \times 100 \%\right)$ of visual, auditory and tactile stimulus- induced plasticity. (c) Plots of conductance modulation range $\left(G_{\max }-G_{\min }\right)$ and on/off ratio $\left(G_{\max } / G_{\min }\right)$ in long-term plasticity measurements with periodical visual, auditory and tactile stimuli under different stimulating intensities. Detailed values of $\Delta G_{\text {peak }}, \Delta G_{\text {mem }}$, retention rate, $G_{\max }-G_{\min }$, and $G_{\max } / G_{\min }$ are summarized in Table S3 below.

\begin{tabular}{|c|c|c|c|c|c|c|c|c|c|}
\hline \multirow{2}{*}{$\begin{array}{c}\text { Stimulus type } \\
\text { Stimulus } \\
\text { intensity (single } \\
\text { pulse plasticity) }\end{array}$} & \multicolumn{3}{|c|}{ Visual } & \multicolumn{3}{|c|}{ Auditory } & \multicolumn{3}{|c|}{ Tactile } \\
\hline & $\begin{array}{c}672 \\
\mathrm{~cd} \cdot \mathrm{m}^{-2}\end{array}$ & $\begin{array}{c}469 \\
\mathrm{~cd} \cdot \mathrm{m}^{-2}\end{array}$ & $\begin{array}{c}230 \\
\mathrm{~cd} \cdot \mathrm{m}^{-2}\end{array}$ & $\begin{array}{l}72.4 \\
\mathrm{~dB}\end{array}$ & $\begin{array}{l}70.5 \\
\mathrm{~dB}\end{array}$ & $\begin{array}{c}68.0 \\
\text { dB }\end{array}$ & $61.2 \mathrm{~N}$ & $22.7 \mathrm{~N}$ & $5.8 \mathrm{~N}$ \\
\hline $\begin{array}{l}\Delta G_{\text {peak }}(\mu S)- \\
\text { potentiation }\end{array}$ & 40.74 & 24.62 & 13.36 & 37.54 & 24.28 & 8.62 & 40.54 & 22.16 & 14.31 \\
\hline $\begin{array}{l}\Delta G_{\text {mem }}(\mu S)- \\
\text { potentiation }\end{array}$ & 32.45 & 19.83 & 12.02 & 31.31 & 21.65 & 9.71 & 36.51 & 20.95 & 14.44 \\
\hline $\begin{array}{c}\text { Retention rate } \\
(\%)- \\
\text { potentiation }\end{array}$ & 79.65 & 80.55 & 89.94 & 83.42 & 89.16 & 112.75 & 90.05 & 94.54 & 100.92 \\
\hline $\begin{array}{c}\Delta G_{\text {peak }}(\mu S)- \\
\text { depression }\end{array}$ & -41.42 & -14.50 & -4.38 & -60.54 & -18.89 & -3.15 & -26.22 & -13.77 & -4.61 \\
\hline $\begin{array}{l}\Delta G_{\text {mem }}(\mu S)- \\
\text { depression }\end{array}$ & -36.45 & -14.53 & -5.27 & -51.60 & -18.28 & -4.09 & -24.92 & -14.05 & -5.75 \\
\hline $\begin{array}{c}\text { Retention rate } \\
(\%)- \\
\text { depression }\end{array}$ & 88.00 & 100.22 & 120.46 & 85.22 & 96.78 & 130.08 & 95.05 & 102.07 & 124.62 \\
\hline $\begin{array}{l}\text { Stimuli } \\
\text { intensity (long- } \\
\text { term plasticity) }\end{array}$ & $\begin{array}{c}672 \\
\mathrm{~cd} \cdot \mathrm{m}^{-2}\end{array}$ & $\begin{array}{c}469 \\
\mathrm{~cd} \cdot \mathrm{m}^{-2}\end{array}$ & $\begin{array}{c}230 \\
\mathrm{~cd} \cdot \mathrm{m}^{-2}\end{array}$ & $\begin{array}{l}72.4 \\
\mathrm{~dB}\end{array}$ & $\begin{array}{l}70.5 \\
\mathrm{~dB}\end{array}$ & $\begin{array}{l}68.0 \\
\mathrm{~dB}\end{array}$ & $66.4 \mathrm{~N}$ & $45.0 \mathrm{~N}$ & $17.1 \mathrm{~N}$ \\
\hline$G_{\max }-G_{\min }(\mu S)$ & 123.25 & 81.61 & 11.31 & 106.19 & 69.99 & 10.97 & 72.00 & 47.73 & 14.09 \\
\hline$G_{\max } / G_{\min }$ & 131.19 & 7.07 & 1.24 & 500.17 & 5.90 & 1.24 & 25.83 & 3.48 & 1.34 \\
\hline
\end{tabular}

Table S3. Summary of $\Delta G_{\text {peak }}, \Delta G_{\text {mem }}$, retention rate, $G_{\max }-G_{\min }$, and $G_{\max } / G_{\min }$ values in Figure S7. 


\section{Mechanical flexibility test of the sSWCNT artificial synaptic transistor}
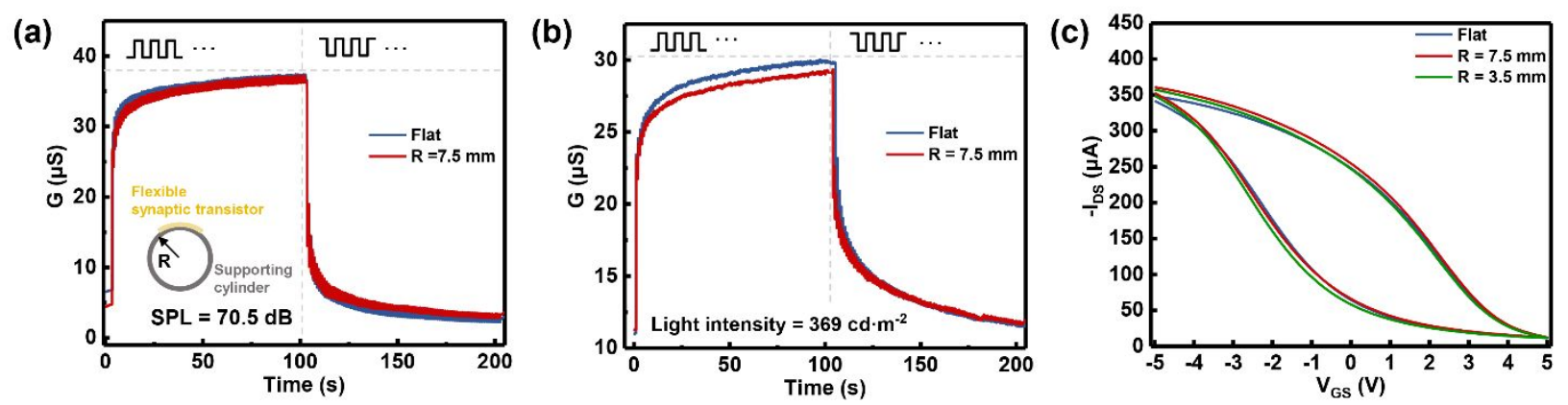

Figure S8. (a-b) Conductance modulation (long-term plasticity) curves of the flexible sSWCNT synaptic transistor ( $W=100 \mu \mathrm{m}, L=10 \mu \mathrm{m})$ measured under relaxed state and bent state (curvature radius: $7.5 \mathrm{~mm}$ ) with (a) periodical auditory stimuli and (b) periodical visual stimuli. The inset in Figure S8a shows the schematic illustration of flexibility test setup. (c) Bi-directional transfer curves of the flexible sSWCNT synaptic transistor ( $W=200 \mu \mathrm{m}, L=5 \mu \mathrm{m})$ measured under relaxed state and bent states with curvature radii of $7.5 \mathrm{~mm}$ and $3.5 \mathrm{~mm}$. 


\section{Retention time measurement of the LTM in multi-store model.}

We measured the retention time of conductance state excited by 100 visual potentiation pulses with light intensity of $469 \mathrm{~cd} \cdot \mathrm{m}^{-2}$ and by 20 visual potentiation pulses with light intensity of $672 \mathrm{~cd} \cdot \mathrm{m}^{-2}$ and the results are shown in the following Figure $\mathrm{S} 9 \mathrm{a}$ and $\mathrm{S} 9 \mathrm{~b}$ respectively.

(a)

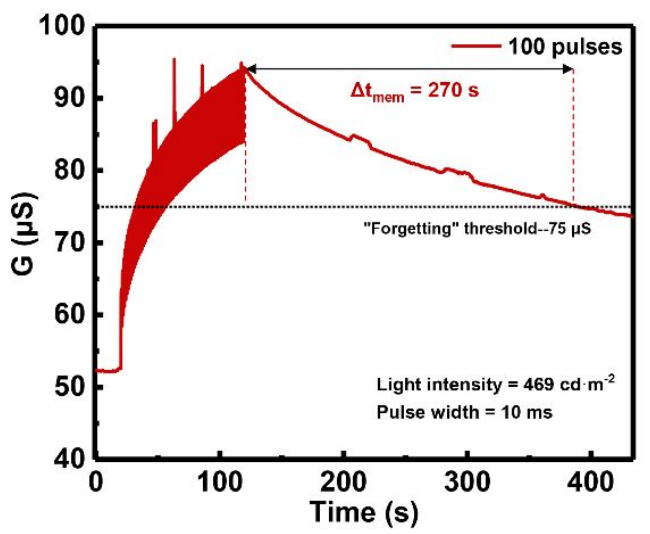

(b)

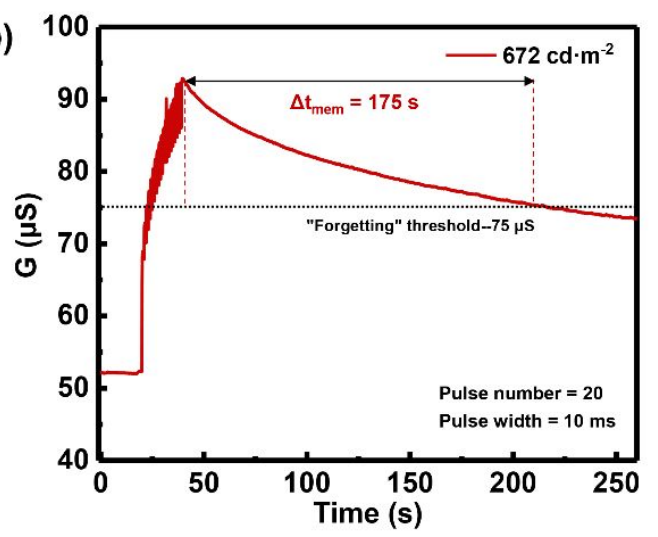

Figure S9. Retention time measurement of with (a)100 visual potentiation pulses with light intensity of $469 \mathrm{~cd} \cdot \mathrm{m}^{-2}$ and (b) 20 visual potentiation pulses with light intensity of $672 \mathrm{~cd} \cdot \mathrm{m}^{-2}$.

The retention times of all three pulses in Figure $4 \mathrm{a}$ and Figure $4 \mathrm{~b}$ are summarized in the Table S4 below:

\begin{tabular}{l|lll|lll}
\hline Pulse width (ms) & 10 & 10 & 10 & 10 & 10 & 10 \\
\hline $\begin{array}{l}\text { Light intensity } \\
\left(\mathbf{c d} \cdot \mathbf{m}^{-2}\right)\end{array}$ & 469 & 469 & 469 & 230 & 469 & 672 \\
\hline Pulse number & 20 & 50 & 100 & 20 & 20 & 20 \\
\hline Retention time (s) & $\mathbf{3 . 3 5}$ & $\mathbf{8 3 . 4}$ & $\mathbf{2 7 0}$ & $\mathbf{0}$ & $\mathbf{3 . 3 5}$ & $\mathbf{1 7 5}$ \\
\hline
\end{tabular}

Table S4. Summary of retention times in multi-store model. 


\section{Comparison of flexible sSWCNT synaptic transistor and other synaptic devices}

We benchmarked the performances of the flexible sSWCNT synaptic transistor in this research with the synaptic devices in the following four articles in terms of 1 . Non-volatile memory retention rate (following the definition of this manuscript) 2. Conductance modulation on/off ratio $\left(G_{\max } / G_{\min }\right) 3$. Conductance modulation range $\left(G_{\max }-G_{\min }\right)$ and 4 . Flexibility. The data is summarized in the following table:

\begin{tabular}{|c|c|c|c|c|}
\hline & $\begin{array}{c}\text { Non-volatile } \\
\text { memory } \\
\text { retention rate } \\
\end{array}$ & $\begin{array}{c}\text { Conductance } \\
\text { modulation on } / \text { off } \\
\text { ratio }\left(G_{\max } / G_{\min }\right) \\
\end{array}$ & $\begin{array}{c}\text { Conductance } \\
\text { modulation range } \\
\left(G_{\max }-G_{\min }\right) \\
\end{array}$ & Flexibility \\
\hline $\begin{array}{c}\text { Sun, Jia, et al. } \\
2^{2018^{1}}\end{array}$ & $\begin{array}{c}\sim 40 \% \\
\text { (potentiation) } \\
\sim 48 \% \\
\text { (depression) }\end{array}$ & $\begin{array}{c}\sim 33 \\
(200 \text { pulses })\end{array}$ & $\begin{array}{c}\sim 230 \mu \mathrm{S} \\
(200 \text { pulses })\end{array}$ & $\times$ \\
\hline $\begin{array}{c}\text { Sarkar, } \\
\text { Debarghya, et al. } \\
2018^{2}\end{array}$ & $\begin{array}{c}\sim 25 \% \\
\text { (potentiation) } \\
\sim 28 \% \\
\text { (depression) }\end{array}$ & $\begin{array}{c}\sim 4 \\
(100 \text { pulses })\end{array}$ & $\begin{array}{c}\sim 35 \% \\
(100 \text { pulses })\end{array}$ & $x$ \\
\hline $\begin{array}{l}\text { Seo, Seunghwan, } \\
\quad \text { et al. } 2018^{3}\end{array}$ & $\begin{array}{c}\sim 10 \% \\
\text { (potentiation) } \\
\sim 46 \% \\
\text { (depression) }\end{array}$ & $\begin{array}{c}\sim 2.1 \\
(100 \text { pulses })\end{array}$ & $\begin{array}{c}\sim 7 \mathrm{nS} \\
(100 \text { pulses })\end{array}$ & $x$ \\
\hline $\begin{array}{c}\text { Subramanian } \\
\text { Periyal, } \\
\text { Srilakshmi, et al. } \\
2^{4020^{4}}\end{array}$ & $\begin{array}{c}\sim 57 \% \\
\text { (potentiation) } \\
\sim 95 \% \\
\text { (depression) }\end{array}$ & $\begin{array}{c}\sim 1.4 \\
\text { (20 pulses) }\end{array}$ & $\sim 30 \mathrm{nS}$ (20 pulses) & $x$ \\
\hline This work & $\begin{array}{c}>80 \% \text { for both } \\
\text { potentiation } \\
\text { and } \\
\text { depression }\end{array}$ & $\begin{array}{l}\text { Maximum: } 131.19 \\
\text { Minimum: } 1.24 \\
\text { (100 pulses) }\end{array}$ & $\begin{array}{c}\text { Maximum: } 123.25 \mu \mathrm{S} \\
\text { Minimum: } 11.31 \mu \mathrm{S} \\
\text { (100 pulses) }\end{array}$ & $\sqrt{ }$ \\
\hline
\end{tabular}

Table S5. Comparison of flexible sSWCNT synaptic transistor and other synaptic devices.

\section{References}

(1) Sun, J.; Oh, S.; Choi, Y.; Seo, S.; Oh, M. J.; Lee, M.; Lee, W. B.; Yoo, P. J.; Cho, J. H.; Park, J. H. Optoelectronic Synapse Based on IGZO-Alkylated Graphene Oxide Hybrid Structure. Adv. Funct. Mater. 2018, 28, 1804397.

(2) Sarkar, D.; Tao, J.; Wang, W.; Lin, Q.; Yeung, M.; Ren, C.; Kapadia, R. Mimicking Biological Synaptic Functionality with an Indium Phosphide Synaptic Device on Silicon for Scalable Neuromorphic Computing. ACS Nano 2018, 12, 1656-1663. 
(3) Seo, S.; Jo, S.-H.; Kim, S.; Shim, J.; Oh, S.; Kim, J.-H.; Heo, K.; Choi, J.-W.; Choi, C.; Oh, S. Artificial Optic-Neural Synapse for Colored and Color-Mixed Pattern Recognition. Nat. Commun. 2018, 9, 1-8.

(4) Subramanian Periyal, S.; Jagadeeswararao, M.; Ng, S. E.; John, R. A.; Mathews, N. Halide Perovskite Quantum Dots Photosensitized-Amorphous Oxide Transistors for Multimodal Synapses. Adv. Mater. Technol. 2020, 5, 2000514. 